\title{
Developmental Stage- and Organ-Specific Expression Profiles of Asparaginyl Endopeptidases/Legumains in the Ixodid Tick Haemaphysalis longicornis
}

\author{
M. Abdul ALIM ${ }^{1)}$, Naotoshi TSUJI ${ }^{1) *}$, Takeharu MIYOSHI ${ }^{1)}$, M. Khyrul ISLAM ${ }^{1)}$, Takeshi HATTA ${ }^{1)}$, Kayoko YAMAJI \\ and Kozo FUJISAKI ${ }^{2,3)}$ \\ ${ }^{1)}$ Laboratory of Parasitic Diseases, National Institute of Animal Health, National Agricultural and Food Research Organization, 3-1-5, \\ Kannondai, Tsukuba, Ibaraki 305-0856, ${ }^{2}$ National Research Centre for Protozoan Diseases, Obihiro University of Agriculture and \\ Veterinary Medicine, Obihiro, Hokkaido 080-8555 and ${ }^{3)}$ Laboratory of Emerging Infectious Diseases, School of Frontier Veterinary \\ Medicine, Kagoshima University, Korimoto, Kagoshima 890-0065, Japan
}

(Received 10 June 2008/Accepted 29 July 2008)

ABSTRACT. We previously identified two cDNAs from the midgut of adult Haemaphysalis longicornis that encode asparaginyl endopeptidases/legumains, HILgm and HILgm2. Functionally, both recombinant HILgm and HILgm2 efficiently digested blood proteins, haemoglobin and bovine serum albumin. Here, we investigated the expression profiles of legumain genes in the developmental stages in the life cycle of $H$. longicornis and in different tissues of adult ticks. Both HlLgm and HlLgm2 were well expressed in larvae, nymphs and adults. Legumain transcripts were expressed specifically in the midgut and were localized in some digestive vacuoles of gut epithelial cells. Furthermore, expression of either transcript was up-regulated by blood feeding in larvae and nymphs, suggesting the important roles of legumains in blood feeding and blood-meal digestion in ticks.

KEY WORDS: arthropods, enzymes, molecular parasitology, tick, vector biology.

J. Vet. Med. Sci. 70(12): 1363-1366, 2008

Ticks are notorious blood sucking ecto-parasites and serve as one of the most important vectors transmitting many bacterial, viral, protozoal and rickettsial diseases from one vertebrate host to another $[13,18]$. They solely depend on host's blood protein to get nutrition and energy essential for their development and reproduction [8]. Haemaphysalis longicornis is a dominant three host tick species in Far East Asia and Australia [10] that transmits many diseases, in particular, theileriosis [7], babesiosis [21] and Q fever to animals and humans [11]. It is believed that ticks have evolutionarily gained molecules that regulate tick biology. As an alternative of toxic chemical acaricide usages, targeting specific molecules which play key roles in tick physiological processes and metabolic pathways regulation including blood feeding and digestion is one of the useful approaches to thwart tick survival and thereby controlling ticks and tick borne diseases [22]. Different proteases have been reported to function as proteolytic enzymes in the midgut of $H$. longicornis [5, 9, 12, 16], Boophilus microplus $[15,19]$ and Ixodes ricinus [20].

Recently, we cloned and partially characterized two cDNAs from the midgut of adult $H$. longicornis that encode asparaginyl endopeptidases/legumains, HILgm [2] and HlLgm2 [1]. Recombinant HlLgm (rHlLgm) and HlLgm2 (rHlLgm2) digested bovine serum albumin and haemoglobin $(\mathrm{Hb})[1,2]$. Previously, we focused on HlLgm and $H l L g m 2$ expression in the midgut of adult $H$. longicornis. However, since blood feeding is obligatory for every devel-

\footnotetext{
* Correspondence to: Tsuj, N., Laboratory of Parasitic Diseases, National Institute of Animal Health, National Agricultural and Food Research Organization, 3-1-5, Kannondai, Tsukuba, Ibaraki 305-0856, Japan.

e-mail: tsujin@affrc.go.jp
}

opmental stage (viz. larva, nymph and adult) of $H$. longicornis and it is very likely that one gene might be expressed in different organs in accordance with its biological relationship, we further investigated each stage and organ specific expression profiles of mRNAs of the two legumain genes in H. longicornis.

In this study, the different developmental and feeding stages of parthenogenetic Okayama strain of $H$. longicornis were obtained by feeding on rabbits as described previously [2] and the animals were treated in accordance with the protocols approved by the Animal Care and Use Committee of National Institute of Animal Health, Tsukuba, Japan (Approval nos. 441, 508, 578). To detect the developmental stages and blood feeding phases specific HlLgm and HlLgm 2 mRNA expression profiles, mRNAs were collected from unfed, $24 \mathrm{hr}, 48 \mathrm{hr}, 72 \mathrm{hr}$ and engorged larvae and nymphs using an RNeasy Mini Kit (QIAGEN) and following the manufacturer's instructions. Reverse transcription (RT)-PCR was performed with a template of $500 \mathrm{ng}$ of total RNA for each $10 \mu l$ reaction mixture using a Takara RNA PCR Kit (AMV) Ver.3.0 (Takara, Shiga, Japan) in accordance with manufacturer's protocol. A $500 \mathrm{ng}$ of each cDNA synthesis product and oligonucleotides which were specific for either $\mathrm{HlLgm}$ (forward primer 5'-CGACGAGCAAATCGTAGTCA-3' and reverse primer 5'-ACTTTTCCGCTTCCTCCATT-3') or HlLgm2 (forward primer 5'CCTTCGCAACAAGCTAAAGG-3' and reverse primer 5'-TCAGAAGTCCTTCGGTG CTT-3') or specific primers for positive control cDNA encoding $\beta$-actin were used to perform PCRs in a final volume of $20 \mu l$. PCR products were electrophoresed in $1 \%$ agarose gel. The quantitative RT-PCR was carried out in a LightCycler 1.5 instrument (Roche Instrument Center AG, Roikreuz, Switzerland) 
A

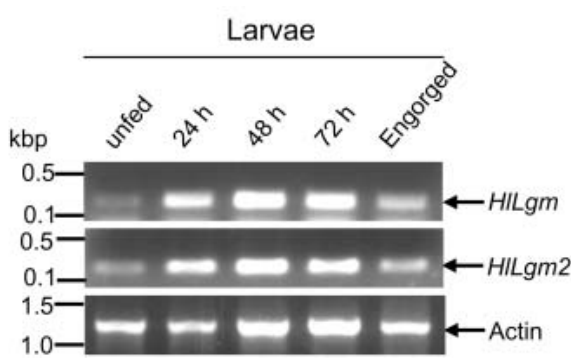

B

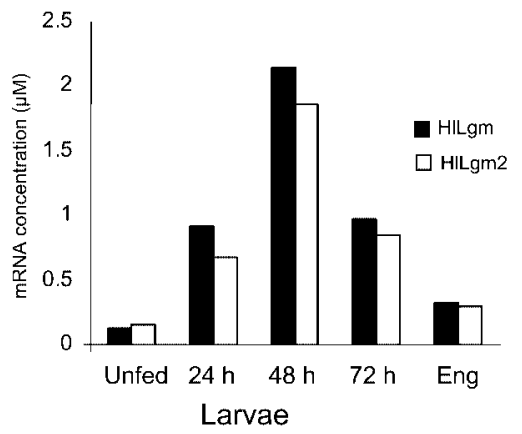

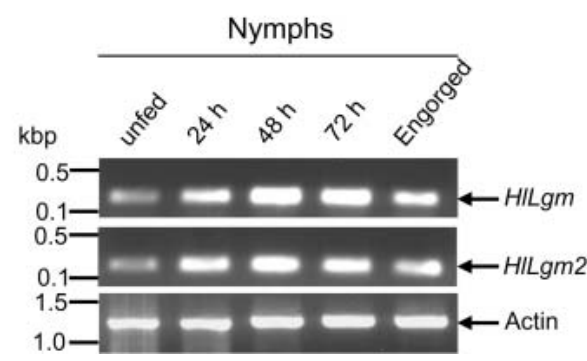

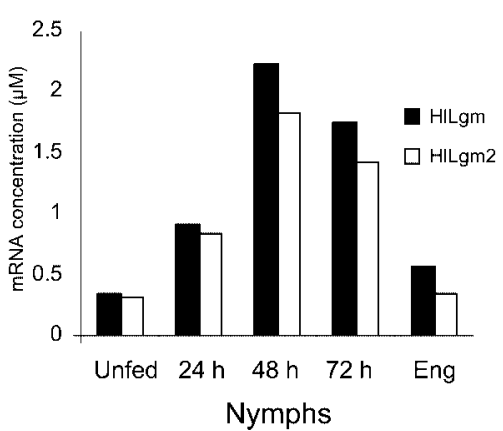

Fig. 1. Expression profile of HlLgm and HlLgm2 genes in the larvae and nymphs of H. longicornis. (A) Reverse transcription (RT)-PCR analysis. The whole body homogenates of larvae and nymphs were subjected to RT-PCR analysis using specific primers for HlLgm and HlLgm2. Arrows indicate the level of gene expression. Actin is shown as an internal control. (B) Real-time PCR was performed using the same total RNA and the same primers specific for HlLgm and HlLgm2 as above. Eng, engorged.

using LightCycler FastStart DNA Master SYBR Green I (Roche Diagnostics GmbH, Nonnenwald, Germany). A 20 $\mu l$ reaction mixture contained $4 \mathrm{mM}$ of $\mathrm{MgCl}_{2}, 0.5 \mu \mathrm{M}$ of each primer (forward and reverse as above), $2 \mu l$ of LightCycler FastStart DNA Master SYBR Green I and $2 \mu l$ of the single-stranded DNA as template. The data obtained were analyzed using LightCycler Software Version 3.5. The results obtained by RT-PCR (Fig. 1A) and quantitative RTPCR analysis (Fig. 1B) revealed that both HlLgm and HlLgm 2 specific mRNAs were well expressed in both larvae and nymphs. Interestingly, HlLgm 2 mRNA expression level was lower than that of HlLgm mRNA during the different phases of blood feeding. Notably, expressions of $\mathrm{HlLgm}$ and HILgm 2 transcripts were up-regulated by blood feeding process reaching to their peaks at $48 \mathrm{hr}$ both in larvae and nymphs, and thereafter declined. Our previous studies revealed similar expression profiles of HlLgm and HlLgm 2 mRNAs in adult $H$. longicornis, however, expression of the genes was culminated at $72 \mathrm{hr}$ of feeding and then declined $[1,2]$. Blood digestion is rapid during the growth phase of feeding which lasts for 1.5 to 2.5 days in H. longicornis nymphs [14] and the proteolytic activities reach to the peak at $72 \mathrm{hr}$ of feeding in adult ticks [4]. Blood digestion during initial stage of feeding (preparatory phase) and in expansion phase when ticks feed rapidly to engorge is very low [3]. Feeding behaviours of larvae are almost similar to that of nymphs, and the present results and our previous findings in adults $[1,2]$ obviously indicate the involvement of the legu- mains in blood protein digestion process in all developmental stages of $H$. longicornis.

To detect the tissue specific expression of HlLgm and HILgm2, individual organs viz. midguts, salivary glands, ovaries, cuticles, tracheae, Malpighian tubules and synganglia were colleted from $72 \mathrm{hr}$ fed adult ticks as described previously [1]. RT-PCR of the mRNAs extracted from these organs as above revealed that both legumain genes were specifically expressed in the midgut tissues (Fig. 2). These results are consistent with our previous observations

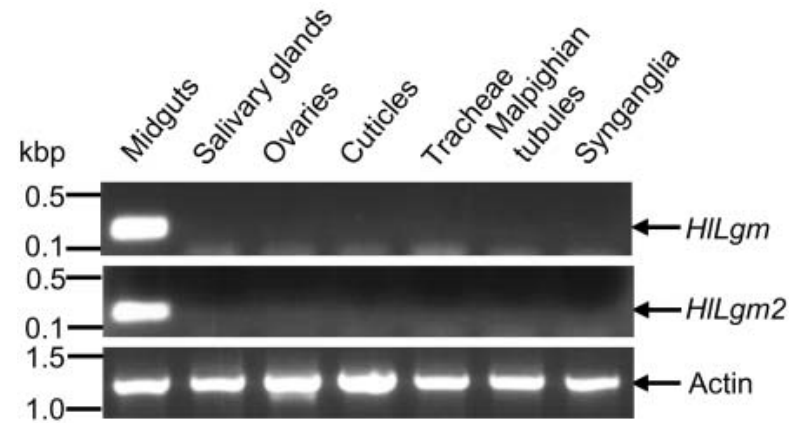

Fig. 2. Organs specific expression profile of HlLgm and HlLgm 2 in the adult $H$. longicornis. The tissues were dissected from three partially fed $(72 \mathrm{hr})$ adult ticks and subjected to RT-PCR analysis. HlLgm and HlLgm 2 transcripts were expressed only in the midgut tissues (Arrows). H. longicornis $\beta$-actin mRNA was used as an internal control. 
Mouse anti-rHILgm2

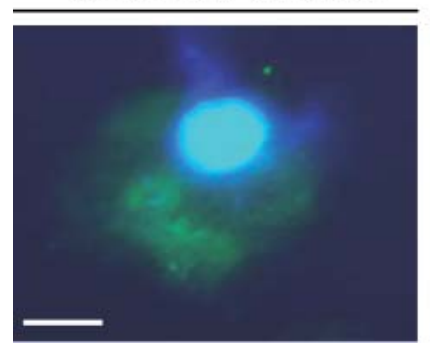

Preimmune

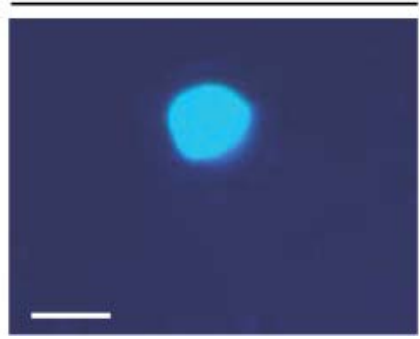

Fig. 3. Intracellular localization of endogenous legumains in the midgut epithelial cells by immunofluorescent staining. The midgut epithelial cells were collected from $72 \mathrm{hr}$ fed adult $H$. longicornis. The cells were fixed in paraformaldehyde and permeabilized with Triton X100. The cells were incubated with either mouse anti-rHILgm2 serum or preimmune serum and visualized with Alexa Fluor ${ }^{\circledR} 488$ (green). The nuclei were stained with DAPI (Blue). Scale bar indicates $10 \mu \mathrm{m}$.

on immunohistochemical localization of endogenous legumains using whole tick sections of adult $H$. longicornis probed with mouse anti-rHILgm [1]. Legumain transcript from the hard tick Ixodes ricinus (IrAE) has also been reported to be expressed solely in the midgut tissues [20]. We next used the immunofluorescence techniques to visualize the intracellular localization of endogenous legumains in the midgut cells as described previously [17]. The cells isolated from the freshly collected midguts of $72 \mathrm{hr}$ fed adult ticks were attached to a glass slide using the Shandon Cytospin $^{\circledR}$ (Thermo Electron, Waltham, MA, U.S.A.), fixed with $4 \%$ paraformaldehyde in PBS $(0.1 \mathrm{M}, \mathrm{pH} 7.4)$ and permeabilized in PBS containing 0.1\% Triton X-100 for 20 min at room temperature. The slides were incubated with mouse anti-rHlLgm2 serum (1:200) only, as we observed that polyclonal antibodies generated against one recombinant legumain reacted notably with both legumain isoforms (unpublished data). The slides were then reacted with green fluorescence-labeled secondary antibody (Alexa Fluor ${ }^{\circledR} 488$ goat anti-mouse IgG $(\mathrm{H}+\mathrm{L})$; Invitrogen, Carlsbad, CA, U.S.A.). The slides were mounted with VECTASHIELD ${ }^{\circledR}$ mounting medium containing 4',6-diamidino-2-phenylindole (DAPI) (Vector Laboratories, Burlingame, CA, U.S.A.) and examined under a fluorescence microscope (Leica, Wetzlar, Germany). Immunofluorescent staining revealed expression of legumains in some digestive compartments of the midgut cells. No reactivity, however, was detected in the cells treated with preimmune mouse serum (Fig. 3). Both rHlLgm and rHlLgm2 were active at neutral to alkaline $\mathrm{pH}$ and the recombinant enzymes digested $\mathrm{Hb}$ and bovine serum albumin optimally at $\mathrm{pH} 7[1,2]$. In ticks, $\mathrm{Hb}$ digestion takes place intracellularly in acidic vacuoles [6]. However, intracellular localization of legumains conceivably suggests their involvement in $\mathrm{Hb}$ digestion cascade in midgut cells.

It is plausible that body organs express genes highly correlated with their biological functions. Midgut specific expression of the legumain genes and up-regulation of their expression levels by blood feeding process suggest their critical roles in blood feeding and blood protein digestion in ticks. Functional characterization of legumains would help to know the prospects of their application as candidate molecules for the control of tick and tick-borne diseases.

ACKNOWLEDGEMENTS. The authors are very much thankful to H. Shimada and M. Kobayashi of the Histopathology Core Group for their help in preparing tick paraffin sections. This work was supported by the Grant-in-Aids (to N. T. and K. F.) from the Ministry of Education, Culture, Sports, Science, and Technology of Japan. This work was also supported by a grant (to N. T. and K. F.) for Promotion of Basic Research Activities for Innovative Biosciences from the Bio-oriented Technology Research Advancement Institution.

\section{REFERENCES}

1. Alim, M. A., Tsuji, N., Miyoshi, T., Islam, M. K., Huang, X., Hatta, T. and Fujisaki, K. 2008. HILgm2, a member of asparaginyl endopeptidase/legumains in the midgut of the ixodid tick Haemaphysalis longicornis is involved in blood-meal digestion. J. Insect Physiol. 54: 573-585.

2. Alim, M. A., Tsuji, N., Miyoshi, T., Islam, M. K., Huang, X., Motobu, M. and Fujisaki, K. 2007. Characterization of asparaginyl endopeptidase, legumain induced by blood feeding in the ixodid tick Haemaphysalis longicornis. Insect Biochem. Mol. Biol. 37: 911-922.

3. Akov, S. 1982. Blood digestion in ticks. pp. 197-211. In: Physiology of Ticks, (Obenchain, F. and Galun, R. eds), Pergamon Press, Oxford.

4. Bogin, E. and Hadani, A. 1973. Proteolytic enzyme activity in the gut of Hyalomma excavatum female ticks. Z. Parasitenkd. 41: 139-146.

5. Boldbaatar, D., Sikasunge, C. S., Battsetseg, B., Xuan, X. and Fujisaki, K. 2006. Molecular cloning and functional characterization of an aspartic protease from the hard tick Haemaphysalis longicornis. Insect Biochem. Mol. Biol. 36: 25-36.

6. Coons, L. B., Rosell-Davis, R. and Tarnowski, B. I. 1986. 
Blood meal digestion in ticks. pp. 248-279. In: Morphology, Physiology and Behavioural biology of Ticks (Sauer, J.R. and Hair, J.A. eds.), Ellis Harwood/John Wiley, New York.

7. Fujisaki, K., Kawazu, S. and Kamio, T. 1994. The taxonomy of the bovine Theileria spp. Parasitol. Today 10: 31-33.

8. Grandjean, O. 1984. Blood digestion in Ornithodoros moubata Murray sensu stricto Walton (Ixodoidea: Argasidae) females. I Biochemical changes in the midgut lumen and ultrastructure of the midgut cells, related to intracellular digestion. Acarologia 25: $147-165$.

9. Hatta, T., Kouji, K., Miyoshi, T., Umemiya, R., Liao, M., Inoue, N., Xuan, X., Tsuji, N. and Fujisaki, K. 2006. Identification and characterization of a leucine aminopeptidase from the hard tick Haemaphysalis longicornis. Int. J. Parasitol. 36: 1123-1132.

10. Hoogstraal, H., Roberts, F. H., Kohls, G. M. and Tipton, V. J. 1968. Review of Haemaphysalis (Kaiseriana) longicornis Neumann (resurrected) of Australia, New Zealand, New Caledonia, Fiji, Japan, Korea, and northeastern China and USSR, and its parthenogenetic and bisexual populations (Ixodoidea, Ixodidae). J. Parasitol. 54: 1197-1213.

11. Ho, T., Htwe, K. K., Yamasaki, N., Zhang, G. Q., Ogawa, M., Yamaguchi, T., Fukushi, H. and Hirai, K. 1995. Isolation of Coxiella burnetii from dairy cattle and ticks, and some characteristics of the isolates in Japan. Microbiol. Immunol. 39: 663671.

12. Huang, X., Tsuji, N., Miyoshi, T., Motobu, M., Islam, M. K., Alim, M. A. and Fujisaki, K. 2007. Characterization of glutamine: fructose-6-phosphate aminotransferase from the ixodid tick, Haemaphysalis longicornis, and its critical role in host blood feeding. Int. J. Parasitol. 37: 383-392.

13. Klompen, H. 2005. Ticks, the Ixodida. pp. 45-55. In: Biology of Disease Vectors, 2nd ed. (Marquardt, W. C., Black, W. C. IV., Preier, J. E., Hagedorn, H. H., Hemingway, J., Higgs, S., James, A. A., Kondratieff, B. and Moore, C. G. eds). ELSEVIER Academic Press, New York.

14. Koh, K., Mori, T., Shiraishi, S. and Uchida, T. A. 1991. Ultra- structural changes of the midgut epithelial cells in feeding and moulting nymphs of the tick Haemaphysalis longicornis. Int. J. Parasitol. 21: 23-36.

15. Mendiola, J., Alonso, M., Marquetti, M. C. and Finlay, C. 1996. Boophilus microplus: multiple proteolytic activities in the midgut. Exp. Parasitol. 82: 27-33.

16. Miyoshi, T., Tsuji, N., Islam, M. K., Kamio, T. and Fujisaki, K. 2004. Cloning and molecular characterization of a cubilinrelated serine proteinase from the hard tick Haemaphysalis longicornis. Insect Biochem. Mol. Biol. 34: 799-808.

17. Motobu, M., Tsuji, N., Miyoshi, T., Xuang, X., Islam, M. K., Alim, M. A. and Fujisaki, K. 2007. Molecular characterization of a blood-induced serine carboxypeptidase from the ixodid tick Haemaphysalis longicornis. FEBS J. 274: 3299-3312.

18. Ostfeld, R. S., Price, A., Hornbostel, V. L., Benjamin, M. A. and Keesing, F. 2006. Controlling ticks and tick-borne zoonoses with biological and chemical agents. Bioscience 56: 383-394.

19. Renard, G., Garcia, J. F., Cardoso, F. C., Richter, M. F., Sakarani, J. A., Ozaki, L. S., Termignoni, C. and Masuda, A. 2000. Cloning and functional expression of a Boophilus microplus cathepsin L-like enzyme. Insect Biochem. Mol. Biol. 30: 1017 1026.

20. Sojka, D., Hajdusek, O., Dvorak, J., Sajid, M., Franta, Z., Schneider, E. L., Craik, C. S., Vancova, M., Buresova, V., Bogyo, M., Sexton, K. B., McKerrow, J. H., Caffrey, C. R. and Kopacek, P. 2007. IrAE-An asparaginyl endopeptidase (legumain) in the gut of the hard tick Ixodes ricinus. Int. J. Parasitol. 37: 713-724.

21. Tsuji, N., Battsetseg, B., Boldbaatar, D., Miyoshi, T., Xuan, X., Oliver, J., H. Jr. and Fujisaki, K. 2007. Babesial vector tick defensin against Babesia sp. parasites. Infect. Immun. 75: 3633-3640.

22. Tsuji, N., Miyoshi, T., Battsetseg, B., Matsuo, T., Xuan, X. and Fujisaki, K. 2008. A cysteine protease is critical for Babesia spp. transmission in Haemaphysalis longicornis ticks. PLoS Pathog. 4: e100062. doi:10.1371/journal.ppat.1000062. 